\title{
THE INTERACTIVE APPROACH AS ONE OF THE WAYS OF LINGUA- SOCIAL ADAPTATION OF STUDENTS FROM LATIN AMERICA IN RUSSIAN UNIVERSITIES
}

\author{
Ekaterina Zvereva \\ Associate Professor of Foreign Languages Department at Law Institute of RUDN University, \\ Russia, zvereva ev@pfur.ru
}

\begin{abstract}
The globalization of modern higher education all over the world, and democratic changes in Russia and its entry into the world educational space have led to an increase in interest in Russia and Russian higher education in the Spanish-speaking world and, as a result, an increase in the number of students from Latin America in Russian universities. There is currently an objective need for an ethnic-oriented approach to educational programs addressed to students - speakers of the Spanish language and culture. Students' belonging to a particular nation with its unique social structure, ethnic and cultural specifics, and national psychological characteristics presupposes the originality of the pedagogical and methodological approaches to teaching Russian as a foreign language.

The research aims to study the main characteristics of lingua-social adaptation of native Spanish speaking students. It also aims to develop a theoretically grounded and experimentally tested ethnic-oriented system of interactive methods to teach Latin American students the Russian language.

Interactive learning is one of the personality-oriented technologies providing self-determination and selfregulation of the student. Modern foreign language teaching methods have been switching from a communicative approach to an interactive approach focused on students' broader interaction. The task is to use the language through the interaction of people with different levels of language command and cognitive activity by overcoming the cognitive conflict, taking into account the students' ethnopsychological and ethnocultural features. The educator's task is to identify the most effective technologies that provide students self-expression as a language identity. The article compares opinions and expectations, provides possible recommendations for further actions, and identifies the basic principles and technologies of interactive learning based on various methodological strategies and techniques.

The research methodology rested on an empirical and experimental approach as the primary tool for analysis. The methodology integrates inductive, comparative, and generalizing techniques, thematic analysis through manual coding, and distributional analysis concerning text layout and key semantic concepts verbal representation. The research methodology also included a survey through respondents' written replies to the questionnaire and statistical data processing techniques.
\end{abstract}

The findings provide evidence that interactive forms of education are in demand in teaching Russian as a foreign language to Spanish speakers at the university since they help make the educational process cognitive and exciting. Their use facilitates perception and dramatically simplifies the assimilation of educational material. Interactive forms of training contribute to all students' involvement in joint activities and teamwork in a team.

These methods allow us to create a favorable psychological climate in the classroom, activate students' academic motivation, guarantee the most effective pedagogical interaction in the educational process, and 
solve sociolinguistic and cultural adaptation of students utilizing language teaching in a Russian university.

Keywords: National psychological characteristics, Oriented learning, Intercultural communication communicative competence, Communication problems, Communicative success, Interactive teaching technologies, Interactive learning, Social character of education.

\section{INTRODUCTION}

Globalization processes leading to the universalization and unification of economic, political, and cultural phenomena in the countries that form the modern human ecosystem currently determine the entire world community's development. In today's multidimensional rapprochement of countries and peoples, forming a single interdependent, multicultural world is an indisputable fact. The increasing mobility, both real and virtual, reinforces the need for successful cultural adaptation and effective communication, which changes the requirements for higher education, including learning foreign languages, which should ensure the ability and readiness of the learners to participate in intercultural communication. The 21 st century witnessed the transformation of higher education in economically developed countries into a mass phenomenon. According to UNESCO, the 21 st century is called the "century of education."

The globalization of modern higher education around the world, as well as democratic changes in Russia and its entry into the world educational space, have led to an increase in interest in Russia and Russian higher education and, as a result, an increase in the number of international students in Russian universities. The purpose of integrating Russian education into the European education system and creating a single educational space is dictated by the socio-economic feasibility and increased mobility of society, the increasing role of knowledge needed to strengthen its intellectual, cultural, social, scientific, and technical potential. The integration of Russia into the European educational space ensures Russian education's competitiveness, which allows us to achieve "recognition" of our educational standards and programs in the market of educational services. It should be noted that the competitiveness of Russian education is also ensured by the fact that Russia has a clear State educational standard at all levels of education; programs are clearly structured, and training is conducted according to a clear and stable schedule. Russian universities have a high potential for improving the national education system's competitiveness in the international market. These include the following: - a solid intellectual and cultural base for development in the Humanities; - fundamental research in the field of natural and mathematical Sciences; - many years of accumulated experience in combining education and research activities, as well as many years of experience in solving scientific and practical problems, development of technology parks and business incubators in partnership with leading research laboratories and institutes; - broad differentiation of the directions of research activities in higher educational establishments (universities, institutes, academies); experience in developing full-fledged scientific personnel in the University environment.

One of the crucial factors of globalization was the inclusion of educational services in the "General agreement on trade in services" of the world trade organization (WTO). (General Agreement on Trade in Services). Despite the ambiguity and risks of long-term consequences of the commercial approach to education, since the late 40 s of the XX century, education for the leading world powers has become a part of foreign policy pursuing geo-economic and geopolitical goals. By the end of the last century, an entire branch of the world economy had been formed - the international market for educational services with an annual sales volume of several tens of billions of US dollars and a volume of consumers of several million people. According to UNESCO experts, foreign citizens' training will become one of the most profitable export types of the XXI century. According to analysts, the competitiveness of a country's national economy depends on a country's ability to ensure the growth of exports of educational services (UNESCO Institute for Statistics, 2020). Training of foreigners is becoming an influential factor in stimulating economic growth. Today, according to the UNESCO International Bureau of education, thousands of higher education institutions from about 140 countries offer their educational services to foreigners, although the main competition is usually between the most developed countries of Western Europe and North America, and Australia and Japan, where more than $4 / 5$ of all international students' study. Significantly, this group of countries accounts for $4 / 5$ of the world's public expenditure on education. By 2025, when the total number of students in the world will increase from today's 97 to 260 million, there will be at least 5-7 million international students (two - thirds 
are from Asia) (Krum, 2013). Russia's share in the international education market regarding the number of international students today is about $4 \%$ (of which about $26 \%$ is in Moscow) (Arefev, 2010). The promotion of Russian higher education in the global education market as a priority direction of development of Russian higher education is enshrined in several Federal documents, approved by the RF Government and the RF President V. Putin in the Federal project "The Concept of export of educational services of the Russian Federation for the period 2011-2020"(The Concept, 2011).

Latin American countries are traditionally exporters of students in the global educational market. They study at universities in Russia, Europe, and America. Cooperation with Russia in the field of education is of considerable interest to Latin American countries. Substantive discussions are regularly held at the state level, and we are ready to build cooperation at the level of individual universities and the level of education systems. Russian higher education is most prevalent in Latin America, and the specific direction is determined depending on the needs of each country. Many experts believe that the introduction of educational standards applied in Russia can help Latin American countries reduce a relatively high social tension level. In General, most countries in the region retain a historically developed interest in studying the Russian language and culture, and there is a desire to strengthen and develop ties in higher education. The main motives for studying Russian as a foreign language among Latin American students are the desire to establish and develop business relations with the Russian side in the field of industry, finance, tourism, and the desire to get higher education in Russian universities.

The Peoples' Friendship University of Russia, represented by the author of this article - is a unique educational project for Russia. Designed as an educational platform for students from various countries, today, the University is a leading Russian University that implements intercultural education principles in practice. Tremendous managerial, scientific and pedagogical experience in the field of intercultural communication, accumulated by teachers and employees of the University, allowed it to become one of the largest research centers in the field of intercultural communication and innovative pedagogy, providing ample opportunities for research aimed at studying the linguistic, ethnocultural and ethno-psychological characteristics of certain groups of international students.

The research's relevance is that there is an objective need for an ethnic-oriented approach to educational programs addressed to international students. According to the Federal Agency, "Sociocenter," the number of Latin American students studying in Russia is quite large and tends to grow (https://na.ria.ru/20190514/1553468787.html). The educational market of Latin American countries has excellent potential for Russian higher professional education. In this regard, it is necessary to stimulate students' interest in this region to study in the Russian Federation. Coming to Russia, students are faced with a different system of social, gender, religious, and, of course, language coordinates from their everyday life. This makes it necessary for researchers to develop didactic and methodological teaching principles that would allow Latin American students to adapt to the new environment as effectively as possible and master their chosen educational program as effectively as possible.

In this regard, the author chose interactive teaching methods as the research object in teaching Russian to students from Latin America in a multi-ethnic group of a Russian University. The study's subject was specific methods of linguistic and social adaptation of students and the purposeful activity of the teacher to create a methodological base that increases the efficiency and comfort of teaching students from this region. The research aims to create a theoretically grounded and experimentally tested ethno-oriented system of interactive methods used to teach Russian to Latin American students.

The purpose and subject of the study determined the range of tasks that must be solved in the process of work: 1) to analyze the theoretical aspects of learning the interaction in a Russian language environment; 2) to identify methods of teaching the students interaction, and to determine the possibility of their use in the lessons of a Russian language; 3) to analyze the modern teaching materials in Russian in terms of using interactive methods in them; 4) to identify a set of interaction methods for teaching Russian to students and check their efficiency in experiential learning; 5) to set guidelines for the teacher of a Russian language on the organization of interaction of students from Latin America in high school lessons.

\section{THEORETICAL BACKGROUND OF THE ISSUE ANDER STUDY}

Students' belonging to a particular nation with its unique social structure, national-cultural specifics, and national-psychological characteristics implies the originality of pedagogical and methodological approaches to teaching Russian as a foreign language. The role of various methods of teaching Russian as a foreign language was re-interpreted under the influence of the works of academician L. Shcherba, who emphasized the importance of knowledge of the native language for learning a foreign language. V. Wagner described 
the essence of the method and the main principles of the national-oriented methodology. The starting point of the national-oriented methodology "Russian as a foreign language "is the position that" the formation of a dual language system inevitably occurs under the influence (spontaneous or conscious) of the system of the native language (intermediary language) already embedded in the individual's brain" (Wagner 1988, p. 7). This influence can be either positive or negative. The national-linguistic orientation is not only a "principle of consideration of native language," but that "the main teaching setting, based on which implemented the principles of consciousness, systematic, functional, communicative orientation, define adequate forms and methods of learning" (Wagner 1988, p.71). Following its methodology, national-oriented manuals were created (Nogueira, 2016, Ermolaeva, 2016).

In recent years, there are more and more supporters of understanding learning a foreign language as a process of intercultural communication: "communication of language personalities belonging to different linguistic and cultural communities" (Gudkov 2003, p. 510). As S. Ter-Minasova writes: "Every foreign language lesson is a cross-cultural practice, it is a practice of cross-cultural communication because every foreign word reflects a foreign world and a foreign culture: behind every word is a national consciousnessconditioned idea of the world" (Ter-Minasova 2008, p. 30). The goal of teaching a foreign language, in this case, is, first of all, to form students' communicative and, as part of it, intercultural competence. By definition of Russian psychologist and linguist I.A. Zimnyaya, "a foreign language as any language system is a sociohistorical product that reflects the history of a nation, its culture, the system of social relations and traditions. Language exists, lives, and develops in the public consciousness, in the people's minds speaking it. It also has the power to isolate and unite peoples, giving a single national character to human communities" (Zimnyaya, 1985, p. 222).

The urgency of developing interactive educational techniques is determined by the goals that modern higher education faces, namely, forming a multicultural personality with knowledge of any foreign language at the level of understanding and free communication.

Interaction is an exchange of actions, planning for a joint activity. Linguistic studies of communication problems are focused on understanding the unit of interaction - dialogue as the most common form of speech, in which individuality is most clearly manifested in the sphere of the psyche, social behavior, and communicative skills. The basis of any learning process is communication and not just scholarly communication, specifically organized and managed, contributing to the formation and development of the individual. In modern pedagogical research, communication is interconnected with the process of interactive learning, during which interpersonal, pedagogically effective, and pedagogically informative communication takes place, and success is achieved in educational activities, in motivational, intellectual, and emotional spheres. Interactive learning is understood to be the one where the interaction of the participants of the educational process with the subject content, with other participants, with their own experience, is a systemforming factor. L. Geykhman underlies that communication not only performs service functions related to the development of objective knowledge and skills but also has intrinsic value - it acts as the goal, content, and result of educational activities (Geykhman, 2002, p. 138).

\section{LITERATURE REVIEW}

Interaction is a means of learning carried out in the forms of joint activities of students when all participants of the educational process interact with each other, exchange information, solve problems, jointly model situations, evaluate the actions of colleagues and their behavior, immerse themselves in the real atmosphere of business cooperation to solve problems. A. Leontiev states that "interaction is a collective activity that we consider not from the point of content or product but in terms of its social organization" (Leontiev, 1972, p.82). The concept of interaction, profoundly studied in social psychology by such scholars as B. Lomov, T. Parsons, A. Leontiev, and J. Schepansky, is closely connected with the concept of "communication." Communication is a multi-faceted process studied by philosophy, sociology, general and social psychology, linguistics, pedagogy, sociology, sociolinguistics, psycholinguistics, and pedagogical psychology, each of which considers a particular facet general; it is a complex problem. It is an essential part of human existence: it exists in all types of human activity. This is the primary condition and mode of existence and development of people. Researchers from different points of view interpret this process; they suggest different approaches to studying it: activity, communication, interaction. Addressing some of the researchers' opinions, we see that L. Bueva develops a different communication approach and its relation to the activity. She believes that "the activity and communication are two interrelated, relatively independent, but not equivalent, sides of a single (individual and social) process of life" (Bueva, 1978, p.45). The point of view of A. Leontiev is that communication should be viewed as a specific aspect of the activity because it is present in any activity as its element (Leontiev 1977). The very same activity can be considered as a necessary condition for 
communication. Simultaneously, several researchers understand communication as a particular type of activity (as a communicative activity), which plays an independent role in human life. B. Lomov regards the activity and communication as two aspects of the social being of a person, his way of life. The essence of this approach is that communication is considered as a specific system of interpersonal interaction, the structure, and dynamics of which cannot be reduced to successively shifting influences, which is characteristic of the activity approach (Lomov, 2006, p. 51-53). A. Bodalev and his successors in their works studied the Gnostic, affective and practical characteristics of communication and their interrelations (Bodalev, 1988). G. Andreeva proposes to characterize communication through the identification of three interrelated options: perceptual, communicative, and interactive. "the perceptual aspect is connected with the process of perception of each other by the partners in the communication and the establishment of mutual understanding on this basis, the communicative aspect of communication, consists of exchanging information between the communicating individuals, the interactive aspect characterizes the peculiarities of the interaction of people and the direct organization of their joint activities (Andreeva, 2005, 2013). It brings us to the consideration that the interactive aspect of communication is a conditional term denoting the characteristics of those components of communication associated with people's interaction, with the direct organization of their joint activities. In joint activities, it is significant for the participants to exchange information and organize an "exchange of actions" and plan everyday activities. A. Leontiev says that in this planning, such a regulation of the actions of one individual by "plans that have ripened in the head of another" (Leontiev, 1977) is possible. Then it makes the activity truly joint when it is no longer an individual but a group that acts as a carrier. Thus, the question of "What kind of "other" side of communication is revealed by the notion of "interaction" can now be answered: that side, which fixes not only the exchange of information but also the organization of joint actions that allow partners to perform some everyday activities for them. Such a solution eliminates the separation of interaction from communication. However, it excludes their identification: communication is organized in the course of joint activities, "in this relation," and in this process, people need to exchange both information and activity, that is, to develop forms and norms of joint action. An adequate understanding of the situation (as in the case of information exchange) and a good leadership style can be seen as an indicator of interaction efficiency. In social psychology, there are many classifications of interaction. Thus, in the classification proposed by A. Leontiev, the situation is divided into socially oriented, subject-oriented, and personal-oriented. Each situation dictates its style of behavior and actions: in each of them, a person "presents" himself differently, and if this self-presentation is not adequate, the interaction becomes exhausting. G. Andreeva (2013) assumes that analysis of research on the problem of interaction in social psychology allows concluding that the partition of a single act of interaction into such components as the participants' positions, situation, and style of actions also contributes to a more thorough psychological analysis of this aspect of communication by making a definite attempt to link it with the content of the activity. It is considered that the interaction in the process of learning a foreign language can be "unilateral" and "multilateral." The first case refers to the educational process organization, in which "the teacher asks, that is, encourages the student to speak, and the student answers." This process is based on the "stimulus - reaction" scheme. Such a training paradigm is characterized by the extensive use of the socalled frontal forms of work. As for the "multi-channel" (i.e., multilateral) communication, then the typical forms of work for it are the groups, in which each student has the opportunity to prove himself as an independent and full participant in certain activities. The model of "multilateral" communication in a lesson has a complex structure of relationships and interrelations between participants in the educational process. E. Vereschagin and V. Kostomarov stressed that according to the research of Russian and foreign scholars this "ability is connected with the presence of a complex of knowledge and skills that allow an individual in the process of intercultural communication to adequately assess the communicative situation, effectively use verbal and non-verbal means, put into practice communicative intentions and verify the results of communication using feedback" (Vereshchagin, Kostomarov, 1986, p. 88). G. Elizarova (2001) mentions that it is also "the ability to carry out intercultural communication by creating the common meaning for communicators of what is happening and, as a result, to achieve a positive result for communication on both sides". E. Passov considers that "communicative competence, which serves as an integrative goal of teaching a foreign language, means cross-cultural interpersonal communication with native speakers within limits specified by the standard"(Passov,2000, p. 48). This definition is consonant with the position of T. Baumer according to whom the communicative competence is "the ability to communicate successfully with other people" (Baumer, 2002, p. 28-30). The above said confirms that the formation of foreign language communicative competence as a strategic goal of teaching a foreign language is associated with a general willingness and ability to communicate and interact. Besides, as mentioned by N. Gubina it is necessary "to have a special cultural self-awareness, realistic self-esteem, the empathy of the other-cultural individual, tolerance, emotional stability, self-confidence, ability to overcome contradictions and avoid conflicts" (Gubina, 2004, p.144). That is characterizing the phenomenon of interaction. For the implementation of 
interaction in any foreign language, knowledge, skills, and abilities are necessary, ensuring the understanding of others and the generation of their programs of speech behavior adequate to the goals, spheres, and communication situations. Purposeful preparation of students for participation in interaction in foreign languages requires an appeal to the methodological foundations of teaching a foreign language.

\section{MATERIALS AND METHODS}

The author of this article is a graduate of the RUDN University with a degree in teaching Russian as a foreign language and has been engaged in this activity since 1991. In this regard, we have accumulated almost 30 years of experience working with international students, including students from the Latin American region.

We developed a systematic and ethnic-oriented approach to the object and subject of research, taking into account the Latin American students' ethnocultural and ethno-psychological characteristics. We used the method of complex theoretical analysis of the phenomenon under study (theoretical analysis of scientific literature on the research issues); survey and diagnostic methods (survey, conversation, questioning of Latin American students and their Russian teachers); - observational methods (direct, indirect, and included observation of the educational process and the learning process of RCTS); - a method for modeling the learning process of RCTS, taking into account the adaptation of students to a different linguistic and cultural environment; - a method for quantitative and qualitative assessment of research results, a method for quantitative and qualitative assessment of research results. The experimental method was used as the research method: the groups of students were divided into experimental groups, where innovative solution methods were used, and the control groups, where the same didactic tasks were solved within the framework of customary conditions. The conditions in which the experiment was performed should be the same in both the experimental and control groups - the so-called invariable conditions. The individual components that have differences are called variable conditions. As invariable conditions, we might mention the same number of students, the level of knowledge in foreign and native languages, the proposed language material, and the teacher's qualifications. Variable conditions depend on the purpose of the experiment. Variable conditions are all those that are deliberately subject to change in the course of the experiment. The author identifies four phases in experimenting. The first phase is the organization. The most significant component of this phase is the development of a hypothesis. The second phase is the implementation. It provides for the planned experiment, which may consist of several stages. The third phase is called the statement: its task is identifying the quantitative and qualitative characteristics of the research results, which serves as the basis for the formulation of a particular pattern. The fourth phase is the interpretation, which explains the results' reasons, proof of their representativeness and reliability. After implementing the mentioned phases, the experiment results are tested in the course of the practice of teaching a foreign language, which means the implementation of what has been achieved into the educational process.

\section{RESULTS AND DISCUSSION}

The problem of communication, organization, value systems, the development of psychological foundations, and technological foundations of instructional communication has been shown and solved by enhancing the individual and the group's capabilities. Intensive learning, based on activity and communication-personal approaches, considers mastering foreign language communication from social and psychological positions. In this relation, M. Bergelson (Bergelson, 2008, p. 38) states that this is a specially organized scholarly communication, during which there are accelerated cognitive enrichment and active personal development using a system of controlled group interactions. The technology of social interaction in teaching communication is the ways and means of ensuring the current, really functioning relationship, the interdependence between the participants of a joint educational activity, during which the mechanisms of a student's formation as a subject of educational interaction and as a subject of communicative activity and communication are identified. Interactive learning is based on interaction with the other (student) as a representative of another culture. With this interaction of two people, four levels are manifested: 1) each of them is a carrier of human consciousness; 2) each of them is the carrier of cultural values created by the people to which it belongs; 3) each of them is a representative of a precise system of ideological values of a particular religious' denomination or organization; 4) each of them is a representative of a social and/or professional group, and with all this, each of them is a unique human individuality determined by gender, age, character, temper, and other human characteristics.

According to our observations, in the course of socio-cultural and language adaptation, a multi-faceted process of interaction between the individual and the new socio-cultural environment occurs, during which Latin American students, having specific ethnic and psychological characteristics, are forced to overcome 
various psychological, social, moral, and religious barriers, and master new types of activities and behaviors. Entering a new society is complicated because students have already mastered their native culture, social norms, values, ideas, rules of behavior, and stereotypes of understanding during the initial socialization at home. Now they need to change the already developed, well-recognized, and predictable social reactions and forms of activity and learn skills and knowledge that will facilitate coexistence with representatives of the new, accepting society, ensure harmonious interaction and mutual understanding, and help them master the necessary skills of linguistic behavior of the individual accepted in this culture.

In the hierarchy of goals of the ethnic-oriented socio-cultural adaptation system of Latin American students, we can distinguish three levels: tactical, strategic, and global. Tactical goals are implemented at each lesson and represent a set of pedagogical and methodological steps aimed at students ' assimilation of the curriculum and minimizing adaptive difficulties that occur at each specific lesson. The system's strategic goal is to minimize students' adaptation difficulties through the Russian language and in the process of learning it. Globally it is the formation of an international student's language personality capable of educational and professional activities in the context of a polylogue of cultures.

From 2015 to 2020, we surveyed a group of one hundred Latin American students from Peru, Bolivia, Ecuador, Mexico, and Colombia. A survey of students studying Russian showed that $39 \%$ of respondents define the role of a teacher as a "mentor," $49 \%$ - as an "assistant and adviser," and only $12 \%$ - as a "partner." We assume that at the initial stage, the teacher of Russian as a foreign language should take a patronizing position towards the Latin American student, take a leading role in the educational process, and be ready to support them. The teacher should gradually give the student more independence and offer him creative tasks that require initiative on the student's part. Firstly, this will allow softening the transition from an authority teacher's image that is familiar to students from Latin America to a partner teacher that is typical for the Russian educational environment. Secondly, it will ensure the establishment of a trusting relationship with the teacher. The students' survey showed that they are very susceptible to praise and censure from the teacher: $84 \%$ of respondents said that the teacher's praise is critical to them. From the above, it follows that praise and public approval of his success are a powerful incentive for the student to continue learning, and excessive criticism from the teacher can cause students to reject the teacher's personality, and as a result, the fading interest in the subject. As shown by the survey, students generally prefer group training: $43 \%$ of respondents indicated the inability to work alone, another $43 \%$ indicated the comfort of learning in a group to some extent, and $0 \%$ of respondents considered the group form of training uncomfortable.

We have already noted that the Modern education system requires improvement of teaching methods, as the trends in education are changing, which is becoming open, innovative, and interactive. Innovative teaching methods should improve language teaching quality, diversify the learning process, and promote motivation to study the subject. Moreover, the critical role is played by "multi-sided" communication, which finds a positive response from Arab students. Its characteristic forms are group ones, in which each student can show their intellectual competence. When organizing "multi-sided" communication, all students' speech interaction takes place, and each of the students' potential is revealed. It is an interactive form that helps to unite the team and create an atmosphere of cooperation. Students have a desire not only to demonstrate their knowledge but also to direct it to the overall result. Performing group interactive tasks also helps to mitigate the situation of evaluating the result, the already mentioned praise-blame paradigm, since the assessment is given to the entire group.

When planning a training course and predicting results, a teacher needs to focus on a specific audience, considering its mentality and ethnopsychological component. In terms of establishing psychological contact and building positive interpersonal relationships, students from Latin American countries are ideal. They are very open, friendly open to communication and show a desire for further interaction. These qualities can and should be used in communication tasks. Students boldly and without hesitation, begin to speak the language they are studying at the initial stage.

Foreign students, of course, find it extremely difficult to adapt for a variety of reasons: environment, climate, culture, educational requests, teacher's manner of explanations and didactic materials, "tutorials on the study of foreign languages do not always fully correspond to the goals and conditions of the learning process. It happens because adult students cannot internalize intuitivelyany speech complexes without explaining cause-effect relationships in grammar and syntax. Besides, the structural, systemic, and cognitive differences between synthetic and analytical languages are not clarified in original didactic materials and stay out of the methodical focus" (Kutieva, Raitskaya, 2018, p. 10489). This point of view is being maintained by Russian researchers O.A. Kazarina and M.V. Kutieva noted that the teachers' humanity and spiritual potential, which they highly value, helps students adapt. Russian University teachers are distinguished by 
their ability to serve selflessly, "the most teacher motivating factors were found to be serving the society, having an internal desire to teach and imparting knowledge to others" (Kazarina, Kutieva, 2018, p. 11083). An essential role in the adaptation of students from Latin America in the Russian educational environment belongs, in our opinion, to the pedagogical tactics of "actividades lúdicas", (recreational activities), which contribute to the development of "skills of joint collective, team activity, improve self-control techniques, motivate them to immerse themselves in the culture of the country, activate discursive practice within the professional environment where the student will later work" (Zvereva, Kutyeva, 2017, p. 9). If we consider the psychological aspect of social adaptation, the leading role here is played by " the relationship of cooperation and interaction between the teacher and students in the educational process and beyond, <...> the so-called non-Directive pedagogy (pedagogía no-directiva), which considers learning as an individual process of professional and moral development and conscious development of personally significant knowledge and skills, development of competencies, supported by the Advisory and guiding multi-channel assistance of a teacher-facilitator" (Kutieva, 2016, p. 367).

The national specifics of Spanish-language communicative behavior are reflected in certain speech manifestations. The Spanish language's influence, which is characterized by lexical and syntactic repetitions, metaphors, and hyperbole, causes increased attention to the logical understanding of the information received and the form of presentation, style of speech, and eloquence of the speaker. Latin American students do not like strict logic and objective evidence, but most of all, they appreciate aphorism and a variety of impressions.

A particular distraction characterizes people from Latin America; they quickly get bored with monotonous activities, so interactive methods allow you to use various game forms in the learning process, allowing you to ensure the assimilation of knowledge without using strict logic. Also, Latin American students have a good sense of humor and can try to turn a misunderstanding into a joke. Moreover, make the joke itself a model of an interactive game. For example, in the law Institute's educational process, it can be a simulation of a situation with ignorance of the host country's laws and any comic situation associated with it. The emotionality and sensitivity of students can help the teacher. Emotions and non-verbal communication at the initial stage of teaching can make up for the lack of language knowledge and make the interactive lesson livelier.

Our survey showed that 92 percent of students prefer interactive learning methods and rate them as the most effective. Also, $84 \%$ of students confirmed that they transfer their love for a relaxed atmosphere and holidays to their educational process attitude. Therefore, we believe that the interactive use of holiday stories applies to country studies and lingua-cultural aspects and the formation of speech competencies of various thematic areas. We use joint readings of the poem to assimilate language clichés, for example, an alternate reading of verse stanzas by different authors on the same subject, for example, on the theme "seasons": Pushkin: "The sky breathed of autumn" or " frost and sun, a wonderful day; "Oh, hot summer, I would love you." Tyutchev: "I love a thunderstorm in early May.," and alike. This method allows students to learn vocabulary on this topic in a relaxed way and get acquainted with Russian culture. In the phonetic plan is to work out the pronunciation. Grammatical terms allow you to establish and work out grammatical relationships, for example, adjective and noun: hot summer, cold winter, and alike.

Songs are also extremely productive materials for creating interactive tasks for developing phonetic, lexical, and grammatical skills. Poems and songs not only help to form socio-cultural competence but also open up an entirely new picture of the world for Latin American students, allowing, by the way, using the theme "seasons" to look at the problems of climate adaptation in a different way, the difficulties of which are mentioned by $96 \%$ of respondents.

Interactive forms of teaching Russian at the law Institute include brainstorming, clusters, role-playing games, and crosswords. The method of "brainstorming" is used in classes on Russian as a foreign language when working with educational material. This method allows you to determine the degree of formation of grammatical skills and language proficiency in General. "Brainstorming" is used to develop students' creative thinking, stimulate their active activity, form the ability to work in a team, and forces students to mobilize their attention, turn to reserve knowledge. As a result, the knowledge that has not been used in practice for a long time becomes active. In particular, the method of "brainstorming" is used in the first year when composing a story based on pictures, in the second year-when answering questions of a debatable nature, in the third year - when constructing sentences based on models of the scientific style of speech. It is advisable to use this method in the form of a competition. In this case, the group is divided into three teams, each of which alternately makes suggestions for models of the scientific style of speech (what is what, what contributes to what, what is what, what results from what). The teacher writes all the examples on the board. Next, the right 
ideas are selected from the total number of ideas, and points are awarded. The winner is the group which accumulated the highest number of points. Note that this method is productive when students are involved in learning and express their opinion on a particular issue.

Role-playing allows you to "lose" a communicative situation that may occur in reality. The role-playing game is based on a scenario that displays a sequence of actions. So, in the third year, the role-playing game "lawyer-client," judge-defendant is widely used in RCT classes. It helps law students prepare for the practice of law and contributes to the formation of professional competence. Law students learn to engage in dialogue with imaginary participants in various legal interactions. At the same time, students follow the roleplaying game scenario: they use speech etiquette formulas, request information about the case's circumstances (crime), and sum up the questioning. In the first year, when studying the topic "Country, language, nationality," a crossword puzzle in the form of a ladder is used. The work is carried out in groups. Students receive cards depicting the sights of a particular country. Then they guess and write down the country's name and select the same-root words denoting the language and nationality of the people living in this country. Students can be asked to solve a crossword puzzle in the second year when studying the topic "types of crimes." It helps to check the level of vocabulary acquisition. The definition of the crime is given, and students must enter its name in the crossword puzzle. For example, what is committed without prior preparation is an unintentional crime; what is committed through negligence is negligent homicide, and so on. In the third year, crosswords are usually compiled when studying specific topics "Tax law," "International law," "Contract law," and alike. These crosswords allow you to correlate common words and legal terminology.

The class's task launches communication processes that push students to interact and, therefore, to negotiate the meaning. A language is learned by using it, and tasks allow us to reproduce situations of natural use. This approach's experience taught us that a classroom task does not intend everything that we carry out in real life. On the contrary, the particularity of the learning context, which is the class itself, offers us the freedom to use activities with a pedagogical purpose. The crucial thing is to provide students with an extra-linguistic purpose (the task), with which and from which the learners use the language in interaction and allow them to practice the linguistic, discursive resources, available strategies, and the development of communication mechanisms that intervene in the process. The need created for its achievement will, in turn, generate new content that must be provided, making learning a more meaningful experience. If the objective of learning is communication (and the author accepts the importance of oral expression of thoughts as a means and goal), then we must, on the one hand, provide our students with all the tools necessary for interaction (characteristics of oral speech, typology of texts, communication strategies, conversation tactics, and others). On the other hand, we will include in our programs such activities that contribute to developing oral speech skills, skills of participation in conversation and negotiation (skills of functional communication, and social interaction). The skills are undoubting issues in almost every area of human interaction.

\section{CONCLUSION}

In conclusion, it should be noted that the development of critical thinking as a constructive intellectual activity is the central idea of interactive methods. Critical thinking is a complex mental process, starting with an acquaintance with new information and ending with a decision.

First, interactive methods are based on students' direct interaction with the educational environment; that is, the reality they reveal the area of experience mastered. This creates a situation that requires the revision of existing experience, without which it is impossible to highlight and underline the field of the unknown. Second, in interactive learning, the student's subjective experience serves not only as an auxiliary material and illustration to the main content of education but as a central source of educational cognition, which also activates self-actualization processes in the framework of determining the ratio of "axiomatic," objective and "subjective" personal knowledge. Third, in the interactive training, the teacher's commitment gives way to the student's commitment, which stimulates self-actualization in revising the existing methods of organizing work on solving serious applied problems. Fourth, anthropo-oriented learning acquires interactive nature in the course of the use of the project, communication, game technologies, technologies that create situations that demand the cognitive, social and physical commitment of students. This ensures the most effective development of self-actualization since there is a revision of all existing potentials and outlines ways to build them up to achieve a result in the course of relevant interactions.

The interactive educational methods and educational technologies considered in this article are aimed, first of all, at increasing students' capacity and their motivation for educational and professional activities. They allow them to move from passive learning to their implementation in real situations of professional activity, which, of course, improves future specialists' quality of training. 
Understanding the process of teaching Russian to Latin American students as a process of intercultural communication allows us to identify participants in the pedagogical process (teacher, student, group) as carriers of a particular ethnic culture, entering into cross-cultural interaction, and clarify the functions of each of the participants in the educational process. It was concluded that every international student has ethnopsychological and ethnocultural characteristics, the ethnocultural experience of a different didactic system. The ethnocultural approach to Latin American students' social adaptation in Russian universities has allowed us to identify the most critical interactive methods to be applied during the learning process. These methods allow us to create a favorable psychological climate in the classroom, activate students' learning motivation, guarantee the most effective pedagogical interaction in the educational process, and solve sociolinguistic and cultural adaptation of students utilizing language training in a Russian University. It should also be noted that interactive forms of education are quite popular in teaching Russian as a foreign language at a law school, as they help make the educational process informative and fascinating. Their use facilitates the perception and dramatically simplifies the assimilation of educational material. Interactive forms of learning contribute to all students' involvement in joint activities and the formation of teamwork in a team. Even in globalization, when cultural borders are sometimes blurred, it is impossible to ignore the ethnopsychological features of a person learning a foreign language. At the initial stage of integration into a foreign linguistic and cultural space, one's own culture and national mentality serve as a support and a kind of Foundation, a measure of all things. In order not to foster rejection of a new culture, a new language, the teacher at the initial stage should be able to find such levers that will arouse interest and motivation. Considering national and cultural specifics allows the teacher to predict the result of their activities, create a favorable atmosphere for learning the language, and maintain interest, facilitated by interactive methods.

The author believes that it is necessary to expand the scope of activities of Russian centers of science and culture in Latin America and promote the intensification of interaction between Russian universities and Latin American universities to create joint projects, modular training, and exchange programs.

Integration of Russian education into the pan-European educational space is necessary because education and science at the present stage are not only cultural but also one of the decisive factors of political and economic development as an effective way of international communication.

\section{ACKNOWLEDGMENT}

This paper has been supported by the RUDN University Strategic Academic Leadership Program. The author received no financial support.

\section{REFERENCE LIST}

Andreeva, G. M. (2005). Psychology of social cognition. Moscow: Aspect Press, 2005.

Andreeva, G. M. (2013). Social cognition and social problems. Journal of national studies, 1 (9): 39-49.

Arefev, A. L. (2010). State and prospects of export of Russian education. Moscow: RUDN.

Baumer, Th. (2002). Handbuch interkulturelle Kompetenz. Zürich: Orell Fussli.

Bergelson, M. (2008). Intercultural communication as an interaction of linguistic and cultural models. Language. Culture. Communication: Collection of scientific papers. Moscow: Gnosis, 2008, pp. 427435.

Bodalev, A. (1988). Psychology of personality. Moscow: MSU Publishing house.

Bueva, L. P. (1978). The Person: activity and communication. Moscow: Mysl.

Concepts of export of educational services of the Russian Federation for the period 2011-2020. Retrieved from http://vi.russia.edu.ru/news/discus/concept/3783

Elizarova, G. V. (2005). Culture and teaching foreign languages. St. Petersburg: KARO.

Ermolaeva, N.V. (2016). Manual del ruso para los hispanohablantes. Moscow: Education.

Geikhman, L. K. (2002). Interactive communication training: approach and model. Perm: Perm State University.

General Agreement on Trade in Services. Retrieved from http://www.vavt.ru/wto/wto/GenATS 
Gubina, N. M. (2004). Formation of students' intercultural competence when teaching business English in an elective course (advanced level, specialty "World economy"). Ph.D. Dissertation, Moscow.

Gudkov, D. B. (2003). Theory and practice of intercultural communication. Moscow: Gnosis.

Kazarina O.A., Kutieva M.V., Orekhova E.Yu. \& Safronova V.A. (2018). Factors contributing to teachers' job satisfaction: The case of Russian Universities. Conference proceedings. EDULEARN 18:1108311090. ISBN: 978-84-09-02709-5 / ISSN: 2340-1117. doi: 10.21125/edulearn.2018

Krum E. V. (2013). Assessment of trends in the world market of educational services in the context of its sustainable development. Retrieved from http://elib.bsu.by/bitstream/123456789/23013/1.pdf

Kutieva M.V. (2016). Practical steps to democratize foreign language education: Foreign experience. Innovation and Multicompetence in Teaching and learning foreign languages. Collection of proceedings. Peoples ' Friendship University of Russia; F. Skarina Gomel State University. Moscow, Pp. 367-378.

Kutieva M.V., Raitskaya L.K., Vygovskaya-kazarina O.A. \& Tyrina T.G. (2018). Authentic and non -authentic tutorials in foreign languages teaching: the case of Russian Universities. Conference proceedings. EDULEARN 18: 10488-10495. ISBN: 978-84-09-02709-5 / ISSN: 2340-1117. doi: 10.21125/edulearn.2018

Leontiev, A. (1972). Problems of mental development. Moscow: Moscow State University.

Leontiev, A. (1977). Psychology of communication. Moscow: Smysl.

Lomov, B. F. (2006). Mental regulation of activity. Selected works. Moscow: Litagent Kogito-Center.

Nogueira, V. (2016). Ruso para hispanohablantes. Herder.

Passov, E. I. (2000). New concept of foreign language education. Moscow: MSU Publishing house.

Ter-Minasova, S. G. (2008). Language and intercultural communication. Moscow: Slovo.

"The Concept of export of educational services of the Russian Federation for the period 2011-2020". Retrieved from http://vi.russia.edu.ru/news/discus/concept/3783/

Vereshchagin E. M., Kostomarov V. G. (1986). Language and culture. Moscow: Progress, 1976.

Wagner, V. (1988). National-oriented methodology in action. Russian language abroad, 1 (111): 70-75.

UNESCO Institute for Statistics. (2020). Retrieved from http:// www.uis.unesco.org

Zimnyaya, I. A. (1985). Psychological aspects of teaching speaking a foreign language. Moscow: Education.

Zvereva E. V., Kutyeva M. V. (2017). Methodical example of theatricalization as a tool for the development of discursive multicompetences. Bulletin of Tomsk state pedagogical University, 8 (185): 9-14. 